\title{
Código de Boa Prática em Matéria de Publicações Científicas ${ }^{(*)}$
}

\author{
Zeferino Ferreira Paulo \\ Diretor do Centro de Documentaçāo Científica do Ministério de Ultramar (Lisboa)
}

A Comissão conjunta FID-ICSU-IFLA-ISO ${ }^{(1)}$, criada e reunida para examinar os meios de promover uma açāo internacional eficaz no sentido de melhorar a atual situação da informação científica, considera que

a falta de disciplina, livremente consentida, em matéria de redação e de publicação de informações científicas, é uma das principais causas do aumento inútil do volume de documentos publicados, das despesas feitas para os imprimir, para os resumir, para os referenciar e para os encontrar.

Em conseqüência disso, a Comissão, por proposta do secretário do Departamento de Análises do ICSU, redigiu sob uma forma tão breve quanto possível um texto estabelecendo as regras que deverão constituir uma lógica obrigação moral a seguir por todos os autores de publicações científicas e a aplicar por todos os redatores (e editores) de periódicos científicos.

$\mathrm{O}$ texto, que se aplica, especialmente, às ciências exatas e naturais e à tecnologia, compõe-se de quatro partes:

1 - A primeira estabelece que um resumo corretamente redigido, e de que o autor é o próprio responsável, deve preceder toda a memória científica.

(*) - Tradução, por Zeferino Ferreira Paulo, autorizada pela UNESCO, do "Code du bon usage en matière de publications scientifiques". Bull. UNESCO Bibl. (Paris) 17 (1): 30-34, 1963. Publicada na revista Garcia de Orta (Lisboa), vol. 12, n² 1, págs. 177-182, 1964.

(1) - FiD: Fédération Internationale de Documentation; ICSU: International Councll of Scientific Unions; INFLA: International Federation of Library Associations: ISO: International Organization for Standardization. 
2 - A segunda define três categorias de textos científicos originais: (memória científica original; comunicação provisória ou nota preliminar; revisões de conjunto ou atualização). Além disso, demonstra o que os distingue e sugere a obrigação de todo o autor de indicar a qual destas três categorias pertence o texto que se propõe publicar.

3 - A terceira parte refere-se à redação dos textos científicos e estabelece, especialmente, a obrigação moral para todo o autor de assinalar qualquer duplicação ou qualquer omissão nas partes significativas do texto publicado.

Por diversas vezes, nestas três primeiras partes, se lembra que é de primordial importância para o futuro da documentação científica a adoção de normas internacionais uniformes, universais que permitirão conseguir:

um método único de redação dos resumos de autor:

um código único para abreviação dos títulos dos periódicos científicos;

um codigo único para a maneira e a ordem por que devem ser feitas as citações bibliográficas numéricas;

um código único de símbolos e abreviaturas de termos técnicos; um código único para a transliteração dos caracteres de um alfabeto para outro;

regras comuns para a preparação de vocabulários técnicos e para a sua equivalência multilíngüe.

A Comissão está convencida de que o sucesso destas normalizações será a única maneira de tornar possível o emprego de processos automáticos para a classificação das informações e das publicações científicas e para as pesquisas que permitam estabelecer rapidamente bibliografias retrospectivas.

Foi para dar exemplo de colaboração e para acabar com a dispersão de esforços (a começar pelos textos internacionais múltiplos e por vezes contraditórios) que a Comissão foi criada, elaborou o texto em questāo e que confia à ISO, em cooperação íntima com todos os outros organismos que ela representa, o cuidado de promover a conclusão rápida daquelas normas ${ }^{(2)}$ para as quais um acordo geral não foi ainda conseguido.

4 - A quarta parte do texto visa os redatores-chefes de períodicos e publicaçōes científicas e considera sua obrigação moral verificar se os autores conhecem e respeitam as disposiçóes que lhe dizem respeito. Recomenda, também, a estes redatores-chefes a autorização da re-

(2) - Ver, na pág. 180, da revista Garcia de Orta, a lista das "Recomendações" pertinentes da ISO. 
produção livre dos resumos dos autores. A Comissão nāo considerou necessário lembrar-lhes, pormenorizadamente, as recomendaçöes da normalização internacional relativas, especialmente, à apresentação dos períodicos e livros, pois elas constituem um dos elementos-base dos seus conhecimentos profissionais.

O texto adotado, unanimemente, pela Comissão foi submetido à Comissão Consultiva Internacional de Bibliografia, Documentação e Terminologia da UNESCO, por ocasião da sua primeira reunião em Paris, de 25 a 29 de setembro de 1961. Esta Comissão, que o aprovou igualmente, foi de opinião que o Código, concebido para as ciências exatas e naturais e para a tecnologia, não poderia ser aplicado às ciências sociais e às ciências humanas sem prévio exame pelas organizações internacionais não governamentais especializadas em tais domínios.

A UNESCO publica e difunde o "Código de boa prática em matéria de publicações científicas", persuadida como está de que o acatamento das regras deste Código:

a) permitirá acelerar a correção da desordem da documentação científica;

b) aumentará o valor das informações que ela contém;

c) e reduzirá as enormes despesas suportadas pelos centros de documentação científica e técnica de todos os países.

\section{Código de boa prática em matéria de Publicaçōes Cientificas.}

\section{I - O resumo.}

1 - Todo o texto de caráter original destinado a ser publicado num jornal ou periódico científico ou técnico deve ser acompanhado de um resumo cuja redação incumbe ao próprio autor.

2 - Enquanto se aguarda uma normalização internacional, o resumo deve ser redigido de acordo com as regras e conselhos reunidos no "Guia para a redação dos resumos de autor", elaborado, impresso, distribuído e periodicamente revisto pela UNESCO (documento NS-37. D 10 a) ${ }^{(3)}$.

\section{II - Natureza do texto.}

3 - O autor, ao remeter o manuscrito ou o original do seu texto à redação do periódico onde o deseja publicar, deverá concretizar, em toda a medida pos-

(3) - Este "Guia", que foi oficialmente adotado pelo ICSU, é reproduzıdo adiante (pág. 180). [O Centro de Documentação Científica Ultramarina fe\% a tradução deste "Guia" (refer. D97)]. 
sível, em qual das categorias de literatura científica original esse texto deve ser classificado:

a) Memória científica original;

b) Comunicação provisória ou nota preliminar;

c) Revisão de conjunto ou atualização.

4 - Um texto pertence à categoria de "memórias científicas originais" quando é redigido de tal modo que um investigador qualificado, suficientemente especializado no mesmo ramo da ciência, seja capaz, a partir somente das indicações fornecidas:

de reproduzir as experiências e obter os resultados que ele descreve com erros iguais ou inferiores ao limite superior especificado pelo autor;

de repetir as observações e formar opinião sobre as conclusões do autor;

de verificar a exatidão das análises e inferências que levaram o autor a essas conclusōes.

5 - Um texto pertence à categoria de "comunicações provisórias ou notas preliminares" quando a sua redação não permite aos leitores verifïcar essas informações nas condições indicadas no parágrafo 4, embora contribua com uma ou várias novas informações científicas.

6 - A "revisão de conjunto ou de atualização" não é destinada à publicação de informações originais; reúne, analisa e discute informações já publicadas respeitantes a um determinado assunto.

\section{III - Redaçāo de texto.}

7 - A introdução historica ou crítica, muitas veżes útil deve ser tão breve quanto possível: o autor evitará redigir uma "memória científica" como se se tratasse de uma "revisão de atualização".

8 - A sintaxe será tão simples quanto possível. As palavras poderão ser encontradas num dicionário corrente. Quando esta exigência não puder ser satisfeita, o autor deverá verificar que os neologismos utilizados pertencem ao vocabulário científico e técnico internacional ${ }^{(4)}$.

(4) - Recomenda-se a indicação da origem dos neologismos utilizados. No caso de o autor ter sido forçado a criá-los, por si próprio, deverá descrever o processo de formaçāo do neologismo, dando a sua etimologia e definição. Em suma, o autor deverá velar pela não deformação do sentido dos termos respeitantes ao vocabulário específico do domínio científico de que se ocupa. 
9 - Na redação do texto, evitar-se-á a omissão total ou parcial dos métodos empregados ou de resultados significativos. Se, por consideraçōes de propriedade industrial ou de segurança, o autor é levado a limitar as informações científicas que ele deseja publicar sobre o tema de que se ocupa, deverá então o texto ser apresentado como pertencendo à categoria b) "comunicação provisória ou nota preliminar", e não como uma "memória". Isto deve constituir para o autor científico uma obrigação moral absoluta ${ }^{(5)}$.

10 - Será feita uma referência explícita a todo o trabalho anteriormente publicado pelo mesmo autor ou por qualquer outro, quando o conhecimento desses trabalhos for essencial para situar o texto apresentado na evolução científica do assunto. Indicar-se-á se essas publicações anteriores constituem duplicação total ou parcial em relação ao texto apresentado.

11 - Em nenhum caso se utilizarão comunicações privadas ou publicações de caráter secreto ou de difusão restrita para fornecer argumentos ou provas ${ }^{(6)}$. relativas:

12 - O autor na redação do seu texto respeitará as normas internacionais à abreviação dos títulos dos periódicos; à ordem dos elementos das referências bibliográficas; aos símbolos; às abreviaturas; à transliteração; à terminologia; à apresentação dos artigos.

Utilizará um sistema coerente de unidades de medidas, que deverá especificar claramente.

\section{IV - Recomendaçöes aos redatores-chefes e editores de periódicos científicos.}

13 - Ao aceitar, para fins de publicação, um artigo científico, o redatorchefe deverá conseguir que o próprio autor indique se o seu texto pertence à

(5) - Admite-se que é evidente para todos que em nenhuma publicação se deverá. conscientemente, deformar a descriçāo dos fatos observados ou dos métodos empregados.

(6) - Não é caso para impedir a alusão a conversas ou a comuniçōes privadas, mas salienta-se que não se afigura legítimo formular uma afirmação ou chegar a uma conclusão reportando-se a uma simples conversa não verificada.

Consideram-se publicações de difusāo restrita as que nāo são acessíveis ao público científico em geral, seja a título gratuito, seja a título oneroso. 
categoria a) "memórias científicas originais", b) "comunicações provisórias ou notas preliminares" ou c) "revisōes de conjunto ou atualizações".

14 - Ao imprimir o texto aceito, o redator-chefe mencionará antes do resumo prévio em qual das três categorias o texto deve ser considerado.

15 - Ao aceitar o texto científico para publicação e enquanto se aguarda a normalização internacional, o redator-chefe assegurar-se-á que o resumo do autor, que deve acompanhar obrigatoriamente o texto, foi redigido de acordo com as indicações dadas no "Guia para a redação dos resumos dos autores" (cf. recomendação $1^{\mathrm{a}}$ parte, 2 . e comentários).

16 - Para assegurar, por toda a parte e em todo o tempo, a reprodução livre dos resumos dos autores, deve declarar-se expressamente nas páginas editoriais que é autorizada a sua reprodução.

\section{Lista das Recomendaçōes da ISO respeitantes a Publicaçōes Científicas.}

ISO-R 4 - Código internacional para abreviação dos títulos de periódicos.

ISO-R 8 - Apresentaçáo de periódicos.

ISO-R 9 - Sistema internacional para a transliteração dos caracteres cirílicos.

ISO-R 18 - Sumário de periódicos ou de outros documentos.

ISO-R 30 - Legenda bibliográfica.

ISO-R 77 - Referências bibliográficas. Elementos essenciais.

ISO-R 214 - Análises bibliográficas e resumos dos autores.

ISO-R 215 - Apresentação de artigos em periódicos.

ISO-R 233 - Sistema internacional para a transliteração dos caracteres árabes.

Projeto ISO no 315 - Transliteração dos caracteres gregos em caracteres latinos.

Projeto ISO no 379 - Transliteração do hebreu.

Guia para redação dos resumos dos autores.

1 - Por "resumo do autor" compreende-se o resumo de um trabalho científico, redigido pelo próprio auior e publicado ao mesmo tempo que o tra- 
balhó, depois de a sua apresentaçäo ter sido exarainada pela redação do periódico que o faz aparecer ${ }^{(7)}$.

2 - O objetivo dos resumos dos autores nāo é somente facilitar a consulta dố periódico que os publica, mas também tornar o trabalho das redações dos periodicos analíticos menos oneroso e mais rápido e contribuir, assim, para o melhoramento geral dos serviços de documentação científica.

3 - O resumo do autor deve recapitular sucintamente os fatos contidos no trabalho e suas conclusōes e chamar a atenção para os novos dados do problema, indicando a sua importância. Deve permitir ao leitor apressado ajuizar, melhor do que somente pelo título, se o trabalho interessa ou não.

4 - Por conseqüêrıcia, pede-se aos autores de todos os trabalhos que forneçam igualmente um resumo de acordo com as diretrizes seguintes.

\section{Redação.}

5 - É preferível usar frases inteiras em vez de uma simples seqüência de títulos: $\mathrm{O}$ autor do trabalho deve ser mencionado sempre na $3^{\mathrm{a}}$ pessoa. Devem empregấi -se termos geralmente aceitos, e nāo apenas os de uso particular. As contraçōes inúteis devem ser evitadas. Presumir-se-á que o leitor tem algum conhecimento do assunto, mas não leu ainda o trabalho. $O$ resumo deve, portanto, ser compreensível por si próprio em que seja necessário reportar-se ao trabalho. (Nunca citará, por exemplo, parágrafos ou ilustraçōes pelo número que apresentam no texto).

\section{Conteúdo.}

6 - Como o título do trabalho é em geral lido como se fizesse parte do resumo do autor, deve evitar-se que a primeira frase o repita. Se, todavia, o título não é suficientemente explícito, a primeira frase indicará o assunto tratado. Regra geral, o início do resumo do autor deve revelar o objeto das pesquisas.

7 - Por vezes é útil indicar a maneira como o assunto foi tratado, por termos tais como: de um modo sucinto, aprofundado, teórico, etc.

8 - O resumo do autor deve indicar os fatos novos observados, as conclusōes tiradas de uma experiência ou de um argumento e, se possível, as novas linhas essenciais das teorias, técnicas, processos, aparelhos, etc.

(7) - Em inglês, o termo synopsis foi adotado pela Royal Socicty de Londres (segundo) a recomendação da Conferência de Documentação Científica efetuada em 1948 sob os auspícios) e pela Conferência Internacional sobre Análises Documentais Científicas promovida pela UNESCO $\mathrm{cm} 1949$. 
9 - Deve conter o nome de todo o novo composto, minério, etc., assim como de todos os novos dados numéricos, tais come uma constante física, etc.; se isso não for possível, deve chamar a atenção sobre o assunto. É ímportante mencionar os fatos e observaçōes novas, mesmo que não digam respeito ao assunto principal do trabalho, senão acessoriamente, pois, caso contrário, estas informações poderão passar despercebidas apesar do seu valor eventual.

10 - Quando o resumo do autor dá resultados, deve indicar o método empregado. Para os métodos novos, o princípio básico, o domínio de aplicação e o grau de exatidão devem ser expressos com justeza.

\section{Remissivas, referências bibliográficas.}

11 - Se no resurio do autor for necessário fazer uma referência para uma publicação anterior, esta referência deve ser sempre redigida da mesma maneira que no trabalho original. Caso contrário as referências devem ser omitidas.

12 - As referencias bibliográficas relativas a periódicos científicos devem ser redigidas conforme o uso estabelecido pelo periódico no qual o trabalho aparece. (A Conferência Internacional sobre as Análises Documentais Científicas recomendou as regras propostas pela Organização Internacional de Normalização, Comissão Técnica 46, sendo os títulos dos periódicos abreviados da mesma maneira que na World List of Scientific Periodicals).

\section{Extensāo.}

13 - O resumo do autor deve ser tāo conciso quanto possível. Só excepcionalmente deve exceder 200 palavras, de forma a poder ser cortado, uma vez impresso, e colado sobre fichas de formato $7,5 \mathrm{~cm} \times 12,5 \mathrm{~cm}$.

\section{Publicação, Línguas e formato.}

14 - A Conferência Internacional sobre Análises Documentais Científicas recomendou que os resumos dos autores fossem publicados numa língua de grande expansão, seja qual for a língua do trabalho original, a fim de facilitar a sua compreensão internacional.

15 - A Conferência Internacional sobre Análises Documentais Científicas recomendou igualmente o uso, seguido por certos periódicos, de reunir todos os resumos de um mesmo fascículo no verso da capa ou em páginas cujo verso corresponda a publicidade, de forma que se possam cortar e colar sobre fichas sem mutilar as páginas do próprio periódico. Para este efeito, os resumos dos autores são impressos com uma mancha de $10 \mathrm{~cm}$, no máximo, a fim de poderem ser colados em fichas do formato $7,5 \mathrm{~cm} \times 12,5 \mathrm{~cm}$. 